\title{
Docência, escola e escolarização - uma entrevista de Michel Foucault para a Periscope em 1975
}

David da Silva Pereira ${ }^{1}$

\section{Resumo}

Em uma entrevista com Jacques Chancel, em 10 de março de 1975, Michel Foucault é indagado sobre a sua docência, a escola, as implicações da família em relação à escolarização, ao ambiente escolar e à atitude dos jovens na escola. Trata-se de um fragmento de dez minutos de uma entrevista com cerca de sessenta realizada para o Radioscopie, programa tradicional do rádio francês. Os elementos que emergem desse diálogo possibilitam, mais de quatro décadas após, pensar a docência e a escola brasileira. Dessa forma e com essa perspectiva, pretende-se ultrapassar a mera descrição para problematizar alguns elementos da formação docente e da construção da relação de ensinoaprendizagem com esse outro - o aluno.

Palavras-chave: Docência; Jovens; Escola; Michel Foucault; Ensino-aprendizagem.

\section{Enseignement, école et scolarisation - entretien de Michel Foucault à Periscope en 1975}

\section{Resumé:}

Dans une interview accordée à Jacques Chancel le 10 mars 1975, Michel Foucault est interrogé sur son enseignement, l'école, les implications de la famille pour la scolarité, le milieu scolaire et l'attitude des jeunes à l'école. II s'agit d'un extrait de dix minutes d'un entretien avec une soixantaine organisé dans le cadre de l'émission radioscopique traditionnelle française Radioscopie. Les éléments issus de ce dialogue permettent, plus de quatre décennies plus tard, de penser à l'enseignement et à l'école brésilienne. De cette façon et avec cette perspective, nous entendons dépasser la simple description pour problématiser certains éléments de la formation des enseignants et de la construction de la relation enseignement-apprentissage avec cet autre - l'élève.

Mots-clés: Enseignement; Jeunesse; École; Michel Foucault; Enseignement-apprentissage.

\section{Introdução}

São seis minutos e vinte e um segundos de um diálogo intenso, curioso e revelador do pensamento foucaultiano sobre a sua docência, sobre estudantes e escolas, sobre a aprendizagem e sobre a responsabilidade dos pais e familiares ${ }^{2}$.

Jacques Chancel conversou com Michel Foucault no âmbito de um conjunto de entrevistas. Essa, em especial, teve cerca de cinquenta e quatro minutos de duração dos quais

\footnotetext{
1 Universidade Tecnológica Federal do Paraná, Campus Cornélio Procópio (UTFPR-CP), Cornélio Procópio, davidpereira@utfpr.edu.br

${ }^{2}$ Disponível em: https://www.youtube.com/watch?v=VjsHyppHizM. A entrevista completa, também disponível no Youtube pode ser acessada em https://www.youtube.com/watch?v=Wt7dk3h9Ruw, disponibilizada em 15.mai.2013, com 79.472 visualizações em 20.dez.2018. Esse fragmento tem início no minuto 8'36" e finda no minuto 14' de um total de 54'36" que compõem a entrevista completa realizada em 10.mar.1975.
}

Periódico Horizontes - USF - Itatiba, SP - Brasil - e019022 
um fragmento foi disponibilizado no Youtube em 05.set.2016 e já contava com 72.138 visualizações no fechamento deste texto.

Mais do que uma mera descrição, pretende-se problematizar as respostas oferecidas por Michel Foucault, compreendendo que se deram ainda no penúltimo quartel do séc. XX e em um país central da economia e do mundo pós-Guerra Fria, e o Brasil vivia o décimo primeiro ano de um regime que duraria ainda outros dez anos - o Regime de 1964 e do Al-5.

\section{O Professor}

A questão inicial desse fragmento de entrevista é, justamente, se Michel Foucault "é favorável ao ensino". Ao não compreender, inicialmente a questão, o filósofo é interpelado pelo entrevistador com a afirmativa de que é, ele, um professor.

Foucault revela, nessa oportunidade, que é um "mínimo de professor", no sentido de que procura não estabelecer com seus ouvintes uma relação de poder marcada pela culpabilização, pela obrigação e pela verificação ou avaliação:

Eu sou um mínimo de professor. Você sabe... eu ofereço cursos no Collège de France muito particulares e que tem por função, justamente, nada ensinar. O que me prende nessa instituição é a impressão de nada ensinar, quer dizer, de exercer diante de um auditório uma relação de poder (FOUCAULT, 1975, 0'13" a 0’37"4).

É, no mínimo, curiosa essa resposta por meio da qual Foucault afirma que o que o prende no Collège de France, na instituição na qual atuará entre 02.dez.1970 e 24.jun.1984, ou seja, durante os pouco mais de 13 últimos anos de sua vida, é justamente a possibilidade de não estabelecer uma relação de poder com os ouvintes, ou seja, não ter sua prática marcada por rotinas tão comuns à docência brasileira como uma lista de alunos, promover a chamada nominal, registrar as ausências, comunicá-las à coordenação pedagógica, ensinar uma série de coisas, verificar se os alunos aprenderam ou não tais coisas.

Assim, a docência descrita por Foucault no longo processo de escolarização resume-se,

\footnotetext{
${ }^{3}$ Tradução livre a partir da escuta da gravação, com foco na ênfase dada pelo autor.

${ }^{4}$ Minuto inicial e minuto final da gravação.

Periódico Horizontes - USF - Itatiba, SP - Brasil - e019022
} 
no trecho a seguir, em três procedimentos com impactos sérios para a relação professor-aluno:

Professor é aquele que diz uma série de coisas que você não sabe, mas que deveria saber - é primeira etapa - que eu chamo de culpabilização se você quiser; como segunda, essas coisas que você deveria saber, eu as sei e eu as ensino - esse o estágio da obrigação. Ao final, eu verificarei se você as sabe -é a verificação (FOUCAULT, 1975, 0'38' a 1'05", grifos meus).

Interessante como, no raciocínio foucaultiano, é preciso partir de uma falta - de uma ausência - da constatação de uma insuficiência no outro para que o processo de obrigar o outro, a partir da culpa, a reproduzir um saber que esse outro da relação - o professor - porta. Tais elementos têm relação com o currículo - o que deve ser ensinado - mas também com a formação docente - o que deve compor a formação inicial dos cursos de Licenciatura no Brasil, mas também e sobretudo, são arranjados em uma relação de extrema violência que inicia com o apontamento do que o outro não tem. O filósofo, preocupado com a relação estabelecida com outro, desmascara, de imediato, a tensão envolvida na relação de ensino-aprendizagem entre o profissional - que sabe - e aquele que está diante dele - que não sabe.

Após a culpabilização, há um agir docente no sentido de fazer com que essa ausência, lacuna ou insuficiência seja suprida. Tal suprimento se dará, agora, ao modo de uma transmissão de saber - daquele que sabe para aquele que não sabe. Essa é a segunda etapa, fundada na obrigação de aprendizagem. Mas não é apenas isso. É preciso ter certeza que o círculo se fechou por meio das verificações, ou seja, são necessários procedimentos de constatação de que aquilo que não era de domínio do aluno seja, ao fim dessa atividade, apreendido por ele. Trata-se de um sistema fechado que depende da existência de muitos que não sabem e que estejam diante de alguém que foi preparado para saber.

Essa relação oculta, certamente, uma série de elementos importantes da relação professor-aluno e do processo de formação docente.

Inicialmente, a relação trabalhada nessa situação verticalizada, da superioridade do professor, parece distanciar-se de algo que o próprio Foucault vai resgatar da Antiguidade, mais precisamente da relação mestre-discípulo, que consiste na amizade. Ela é essa atividade de um mais velho em relação a um mais moço, fundada na confiança e na convivência contínuas a partir da qual se constituirá no outro, em primeiro lugar - o desejo de saber - e, em segundo lugar - as 
condições para essa aprendizagem. Sem dúvida, parece que essas etapas não estão presentes na descrição do ofício docente por Foucault em 1975.

Por sua vez, o processo de formação inicial docente, que hoje se dá por meio dos Cursos de Licenciatura ${ }^{5}$ no Brasil, possui inúmeras lacunas e toma ainda o licenciando como um educando da Educação Básica, destituído de autonomia, e longe de se emancipar. Isso porque esse professor em formação permanece silencioso diante de alguém que sabe. Mais uma vez, o que se assiste é um "processo de transmissão" daquilo que se deveria saber para aquele que deve aprender, posto que em preparação para o exercício profissional da docência. Lamentavelmente, nem a primeira nem a segunda afirmação são verdadeiras. Em muitos casos, aquele que ensina o faz a partir de uma titulação acadêmica que não exatamente passou pela Licenciatura ou pela docência da Educação Básica. Já o licenciando, nem sempre aprende em função da comunicação truncada, da distância estabelecida pelo mestre e das insuficiências de seu próprio percurso escolar.

Assim, um ensina e o outro aprende. Melhor dizendo, ensina-se como pode e aprende-se como é possível. Essa situação é mantida há anos em face da visão produtivista da Universidade brasileira, que concentra seus processos de seleção e de concurso públicos para docentes em aspectos quantitativos de produção de artigos e livros em vez de primar pela análise da didática, da metodologia de ensino e da capacidade de estabelecimento de uma relação a partir desse que se apresenta como candidato a professor de uma Licenciatura.

Mais uma vez, capacidade de pesquisa ou de investigação é muito diferente de docência. Em alguns países, como a França, há dois postos distintos. O investigador e o professor. Há quem se dedique exclusivamente às pesquisas, suas metodologias e contribuições para o avanço da ciência. Há, por outro lado, aquele que vai ensinar e que tem como pressuposto a capacidade de construção de relações de ensino-aprendizagem com outros seres humanos.

Contudo, de volta ao caso francês descrito por Michel Foucault, parece que sua docência

\footnotetext{
${ }^{5}$ Como uma das possibilidades na forma de uma modalidade de Graduação, primeira etapa da Educação Superior (art. 21, II, da LDBEN - BRASIL, 1996), mas também, desde jul.2015, por meio das Segundas Licenciaturas e dos Programas de Formação Docente. As primeiras, voltadas à habilitação em um segundo campo do conhecimento, por meio das práticas e estágios próprios desse novo campo. Os segundos, como processo de complementarização da formação recebida em cursos de Bacharelados, voltada a professores em atividade e sem habilitação em razão da não terem cursado a formação pedagógica própria, por meio desse Processo oferecida, tudo conforme a Resolução CNE/CP n. 02/2015.
}

Periódico Horizontes - USF - Itatiba, SP - Brasil - e019022 
se refere à comunicação anual do andamento de suas investigações. Não se trata de um diálogo com os ouvintes, mas de uma aula-magistral ou conferência após a qual não se prevê questões. Dessa forma, trata-se de um monólogo realizado por aquele que ocupa a tribuna ou mesa principal. É exatamente isso o que se depreende dos Cursos de Foucault no Collège de France. Ano após ano, ele comunica a um público imprevisível, mas sempre numeroso, o andamento de suas investigações realizadas nos últimos doze meses. É uma comunicação sem debate. Uma conferência a um público cambiante, fiel ou infiel, mas silencioso. As menções de que essa relação com a plateia inquietavam, ainda mais Foucault, no início dos Cursos também é curiosa. Segundo esses relatos reproduzidos, com o mesmo texto na forma de uma advertência, Foucault esperava estabelecer outras possibilidades de relação com um público menor, ouvir em vez de apenas falar, interessar-se por possibilidades de derivações ou críticas a partir de seus relatos, mas a natureza do Collège de France impedia tal exclusão dos ouvintes:

No Collège de France, os cursos são livres. Vêm escutar os cursos a gente que vem, não importa quem. Tanto um coronel quanto um estudante de catorze anos. Se se interessa, vem. Se não interessa, não vem. Quem é esse que avalia, que está sob a avaliação do outro? É aquele que ensina - aquele que vem $e$ apresenta o seu trabalho a um auditório realizado ao longo do último ano (FOUCAULT, 1975, 1'07" a 2'10").

Novamente, Foucault toca em um ponto chave da atividade docente, objeto de inúmeras resistências por esses profissionais da Educação - a avaliação. Impressiona o quanto a classe resiste às formas de avaliação do seu trabalho, ao acompanhamento dos coordenadores e diretores e resiste a qualquer forma de acompanhamento. Inclui-se nesse procedimento de autodefesa a recusa de estágio e de acolhida de licenciandos para atividades, trabalhos pontuais ou práticas docentes daqueles que estão no curso da formação.

Essa aversão à avaliação por aqueles que a têm em seu fazer profissional é, fundamentalmente, um indício de que essa atividade pode ser utilizada contra o avaliado. Isso para responsabilizá-lo como único culpado pelo fracasso na aprendizagem. Do que se trata? 0 professor se vê no lugar do aluno ou ele não acredita na eficácia dos instrumentos?

Foucault prossegue em sua entrevista ao afirmar que ele também "trava" por desconhecer o pensamento de seus ouvintes sobre seu trabalho. 
Em seguida, é a escola o objeto da discussão.

\title{
A escola
}

A questão colocada por Jacque Chancel, em seguida, é a de que a escola parece castrar a curiosidade dos alunos. Foucault responde que:

\begin{abstract}
A primeira coisa que se deve aprender ao estudar qualquer coisa é que o saber é ligado profundamente ao prazer. Há, certamente, uma maneira de erotisar o saber, de torná-lo intensamente agradável. Parece que o professor nem sequer é capaz de revelar isso. O professor parece ter por função demonstrar como o saber é desagradável, triste, cinzento. Creio que certamente há razões para tanto, mas é fundamental saber o porquê de nossa sociedade mostrar que o saber é triste, basta ver o número de pessoas que são excluídas do saber... Eu creio que há um prazer intrínseco ao saber (FOUCAULT, 1975, 2'38" a 4'20").
\end{abstract}

Foucault ressalta que a escola foi transformada em um lugar triste, pouco acolhedor e mesmo destinado a derrotar as pessoas. Trata-se de uma eliminação gradativa dos menos adaptados, por questões familiares pretéritas ao ingresso na escolarização. Nesse sentido, há uma concordância com os argumentos contemporâneos de Bourdieu \& Passeron (1970), acerca da escola como instituição reprodutora e aprofundadora das desigualdades sociais. Isso porque a escola implementa um sistema contínuo de exclusões e de marginalizações ao invés de atentar para os que mais precisariam dela, por meio de seus educadores. A tão mencionada bagagem acumulada pelo sujeito fora da escola, por meio de outras experiências, é o elemento preponderante para o sucesso escolar. Por outro lado, um autor como Bernard Charlot (2011) dirá que o "monstro" do fracasso escolar atormenta alunos e professores e tem como vasão esse mesmo processo de culpabilização referido por Foucault no início do diálogo. A questão é, então, justificar que o professor fez tudo o que estava ao seu alcance e o fracasso escolar é culpa do aluno, de sua família, da pobreza, etc.

Vê-se que tais descrições não promovem ou estimular a aprendizagem. Pelo contrário, tomam-na como uma tarefa difícil, a qual deve-se realizar muito esforço para que se possa sobreviver nesse ambiente hostil chamado escola. Especialmente hostil aos filhos das classes pobres, curiosamente e cada vez mais, a mesma de boa parte dos professores da Educação Básica 
em atividade no Brasil, desde 1988.

O direito à educação, previsto na Constituição de 1988, gerou a necessidade de garantia de que toda criança e adolescente brasileiro estivessem na escola. Para tanto, um grande esforço de professores foi iniciado, e prossegue, para suprir a necessidade de profissionais em vários campos do saber. Tal processo foi responsável, não apenas pela inclusão de milhões de crianças que jamais veriam a escola como lugar de convívio, como, também, pela formação e exercício profissional de milhares de professores que tiveram acesso a essa escola pública nas primeiras gerações em que tal direito começa a ser implementado.

O mesmo Charlot retoma a questão do fracasso escolar para dizer que os alunos vão para a escola para passar de ano em vez de aprender. Dessa forma, fariam o esforço mínimo para assegurar a menor nota ou estratégia capaz de assegurar tal resultado. Numa sociedade da informação e da pesquisa, os jovens trilhariam um caminho marginal no interior da própria escola. Haveria que se indagar se o vocabulário empregado em sala, a forma como o diálogo é estabelecido e como o respeito e a disciplina do próprio educador são demonstradas ao aluno.

Isso porque parece ainda fundamental no aprendizado de seres humanos a questão do modelo. A prática do educador parece ser mais eficaz, diante da criança e do adolescente, aliada à coerência desse profissional, do que propriamente alguma estratégia ou metodologia inovadora de ensino. Dessa forma, resume Charlot, o importante é fazer o que o professor disse, não bagunçar, ouvi-lo e passar de ano. Para ele, compreender a lógica do aluno é um primeiro passo importante para enfrentar esse desafio do fracasso escolar.

\section{A responsabilidade dos pais e o significado do diploma}

A escola como um lugar de sofrimento é apontada por Charlot como um risco para essa instituição e para o bem-estar de todos os envolvidos. Foucault também enfrenta essa questão, que passa pela responsabilidade dos pais e responsáveis pela criança nesse processo de ensinoaprendizagem. Sua resposta é a seguinte a partir dessa questão:

Creio os parentes produzem, com efeito, uma verdadeira angústia às crianças diante do desafio do saber, não importando o saber das crianças. Os parentes

Periódico Horizontes - USF - Itatiba, SP - Brasil - e019022 
consideram sua própria glória, seu sacrifício, seus projetos de futuro, às crianças. Creio que a pressão que os parentes exercem sobre as crianças é repleta de angústia. E as crianças, em geral, experimentam isso, percebem essa angústia dos parentes e isso, penso, pesa negativamente sobre as crianças (FOUCAULT, $1975,4^{\prime} 52$ " a 5'49").

Novamente, os sonhos dos pais e as expectativas que detêm em relação ao futuro de seus filhos parecem se descolar da realidade, daquilo que é expressado por professores e por educadores nas escolas. Percebe-se essa situação, em particular, na ansiedade de muitos que querem acelerar o processo de escolarização de seus filhos, por vezes, fundada em suposta "super-habilidade ou capacidade" que não resiste a uma avaliação mais cuidadosa pelos administradores escolares, e que precisa ser avaliada no contexto de cada realidade escolar.

A questão final acerca dessa escola, desse processo de escolarização e do que ele provoca nas crianças vem por meio da discussão sobre o diploma como sanção: "Você sabe que o diploma se constitui como uma espécie de valor de mercado do saber. Permite, igualmente, demonstrar para aqueles que não o detém, que não é capaz de saber. É isso que dá sentido pleno a um diploma - o que ele vale para aqueles que não o tem" (FOUCAULT, 1975, 5'50" a 6'10").

Essa é a última afirmação desse fragmento de entrevista de 1975, o diploma vale para aqueles que não o detém. Seria necessário, nesse raciocínio, avaliar os impactos do acesso à escolarização como direito no Brasil às camadas mais pobres. É justamente quando essas chegam à Universidade que os diplomas da Educação Superior nacional sofrem contínuas desvalorizações. Nem mesmo o acesso aos Cursos de Pós-Graduação, outrora objetos de distinção, são capazes de assegurar posições no campo profissional ou mesmo em escolas.

\section{Considerações finais}

O que se tem desses poucos mais de seis minutos de fragmentos de uma gravação é um conjunto de elementos que não foram pronunciados sobre o Brasil ou na atualidade. Trata-se da França, de 1975, na percepção de um filósofo, de um intelectual, muito engajado com as questões sociais de seu tempo, mas, por outro lado, um hipercrítico de si e da escola.

De qualquer forma, há indicações precisas sobre aquele que ensina, sobre esse ambiente escolar e sobre o papel dos pais e dos diplomas ou certificados no imaginário de crianças e de

$$
\text { Periódico Horizontes - USF - Itatiba, SP - Brasil - e019022 }
$$


adolescentes. Saber o que os anima, além da obrigação de ir à escola, no Brasil do direito à escolarização travestida de direito à Educação significa um esforço de compreensão do papel da escola, no presente, e dos sujeitos que envolvem um trabalho fundamental que, apesar de aprofundar as desigualdades sociais como querem Bourdieu \& Passeron (1970), ainda significa um objeto de desejo das classes populares.

Por outro lado, o acesso precisa ser problematizado assim como as condições nas quais se dá essa permanência de crianças e adolescentes em instituições escolares por longas jornadas diárias enquanto os seus pais podem, em paz, vender sua força de trabalho no mercado.

\section{Referências}

BOURDIEU, P.; PASSERON, J. C. La Reproducción: eléments pour une théorie du système d'enseignement. Paris: Minuit, 1970.

BRASIL. Lei $n^{\circ}$ 9.394, de 20 de dezembro de 1996. Institui a Lei de Diretrizes e Bases da Educação Nacional. Brasília: Congresso Nacional, 1996.

BRASIL. Conselho Pleno do Conselho Nacional de Educação. Resolução n. 02 de X de julho de 2015. Formação dos Profissionais da Educação para o Magistério da Educação Básica. Brasília: CNE/CP, 2015.

CHARLOT, B. Existe o Fracasso Escolar? [Entrevista concedida a]... [2011?] 13'35". Disponível em: https://www.youtube.com/watch?v=1HUJQlduYzk. Acesso em: 24 de dezembro de 2018, $13^{\prime} 35^{\prime \prime}$.

FOUCAULT, M. Michel Foucault à propôs de l'école. [Entrevista concedida a] Jacques Chancel. Radioscopie (Philosophes): Jacques Chancel reçoit Michel Foucault, 10 de abril de 1975, 6'21'. Disponível em: https://www.youtube.com/watch?v=VjsHyppHizM. Acesso em: 24 dez. 2018.

Recebido em dezembro de 2018.

Aprovado em abril de 2019. 